\title{
EL ENDEUDAMIENTO EXTERNO DE RUSIA: DINÁMICA, ESTRUCTURA Y RIEGOS EN LAS CONDICIONES DE LAS SANCIONES ECONÓMICAS DE LOS PAÍSES DE OCCIDENTE
}

\author{
TATiana Sidorenko
}

\section{INTRODUCCIÓN}

Tras la Desintegración de la Unión Soviética en diciembre de 1991, Rusia emprendió el camino hacia la inserción en la economía mundial, lo que suponía la colaboración con las instituciones financieras internacionales, tales como el Fondo Monetario Internacional (FMI), el Banco Mundial y el Banco Europeo de Reconstrucción y Desarrollo (BERD), entre otros, así como la participación cada vez más activa en los mercados internacionales de capital. En la década de 1990, Rusia recurrió principalmente a los préstamos del FMI, Banco Mundial y BERD, que se le concedían para apoyar la transición hacia una economía de mercado. Posteriormente, las empresas y bancos rusos, inclusive controlados por el Estado, han empezado a endeudarse con los bancos europeos y norteamericanos, lo que originó su profunda dependencia de los créditos de dichos bancos y el crecimiento de la deuda exterior corporativa de Rusia.

La incapacidad de llegar a un acuerdo en cuanto a la crisis en Ucrania entre Rusia, por una parte, y los Estados Unidos y la Unión Europea, por la otra, empujó a los últimos a adoptar contra Rusia sanciones de carácter político y económico, que han sido endurecidas a su vez en septiembre de 2014. Como consecuencia, los gobiernos de Estados Unidos y de la Unión Europea han prohibido a sus bancos dar préstamos a las compañías y bancos rusos controlados 
por el Estado. Dada la alta dependencia del sector no financiero y del sector bancario ruso de los mercados financieros internacionales, el problema del endeudamiento externo de Rusia adquiere en dichas condiciones una actualidad especial y lleva altos riesgos para el desarrollo de la economía rusa a largo plazo. Últimamente la caída de los precios del petróleo, principal producto de exportación de Rusia, así como la depreciación del rublo, moneda nacional de ese país euroasiático, han condicionado el empeoramiento de su situación económica y la probabilidad de que la economía rusa entre en recesión a partir de 2015.

El objetivo de este artículo es analizar la dinámica del endeudamiento externo de Rusia desde el momento en que ese país se ha convertido en un Estado independiente hasta la fecha, los cambios que han ocurrido en su estructura y los riesgos que las sanciones de Occidente llevan para la economía nacional.

\section{ANTECEDENTES HISTÓRICOS ${ }^{1}$}

Como se sabe, durante gran parte de su historia la Unión Soviética ocupó un lugar privilegiado en cuanto a solvencia crediticia, lo que determinaba el grado de credibilidad por parte de los acreedores occidentales. Sin embargo, durante la perestroika se manifestó con claridad una tendencia al aumento del flujo de recursos financieros del extranjero, lo que condujo a un crecimiento de la deuda externa que no fue proporcional a su solvencia.

Dos factores principales contribuyeron a la concesión masiva de créditos. Primero, el interés oficial por endeudarse, pues prevaleció el concepto de que el desarrollo a crédito representaba un camino eficiente y aceptable para la nación. Además, el gobierno soviético se vio obligado a recurrir a los créditos para satisfacer los requerimientos de mercancías de consumo interno y hacer frente a la presión de déficit presupuestario del país. El segundo factor

${ }^{1}$ Véase Boris Smitienko y Tatiana Sidorenko, "El endeudamiento externo de Rusia: situación actual y perspectivas", Comercio Exterior, vol. 54, núm. 11, noviembre de 2004, pp. 988-998. 
fue la confianza de los acreedores occidentales en la estabilidad y la solvencia de la URSS y sus intenciones de fomentar los cambios en pro de una economía de mercado. Como resultado, la deuda externa aumentó de 28300 millones de dólares en 1985 a 95100 millones en 1991, de los cuales 57200 millones correspondieron a deuda contratada con gobiernos extranjeros y 37900 millones de dólares a endeudamiento pactado con bancos y compañías extranjeras. ${ }^{2}$ Posteriormente, aquel monto creció a 103000 millones de dólares, debido a la acumulación de los intereses demorados. Sin embargo, el aumento del flujo de los recursos financieros provenientes del exterior no estuvo acompañado de una estrategia nacional para la asignación de estos recursos y la amortización de la deuda externa.

La caída drástica de los ingresos por exportación en 1991 agravó el problema de endeudamiento externo de Rusia. Lo último llevó a la suspensión de los pagos del principal de los créditos otorgados por los bancos comerciales de los países de Occidente y la congelación de las cuentas en moneda fuerte de empresas nacionales y particulares.

$\mathrm{Al}$ acentuarse la desintegración de la URSS surgió el problema de cómo se cubriría el servicio de la deuda externa. El resultado final de las reuniones de los representantes de las antiguas repúblicas soviéticas fue el reparto de la deuda externa, así como de los activos de la URSS entre las últimas de acuerdo con un índice agregado compuesto por la participación de cada una en el ingreso nacional, la población y las exportaciones de 1986 a 1990. Los sucesores más importantes fueron Rusia (61.34\%), Ucrania (16.37\%), Bielorrusia $(4.13 \%)$ y Kazajistán $(3.86 \%)$.

En 1992, Rusia presentó la iniciativa de asumir la responsabilidad por el pago de la deuda externa de todas las que fueron las repúblicas soviéticas y que en ese momento formaban parte de la Comunidad de Estados Independientes (CEI). A cambio, aquellas tenían que renunciar a sus partes en los activos y propiedades de la URSS en el exterior. Todas las repúblicas, excepto Ucrania,

${ }^{2}$ V. Andrianov, "Problemy vneshney zadolzhennosti Rossii I vozmozhnnye puti eye resheniya", en Vneshniy dolg Rossii i problemy ego uregulirovaniya, Moscú, 2002, p. 25. 
apoyaron esta iniciativa y en 1992 firmaron con Rusia los acuerdos correspondientes. A principios de 1993, Ucrania hizo lo mismo. En abril de 1993 los países de Occidente reconocieron a Rusia como el único Estado responsable de la deuda externa de la URSS.

\section{Dinámica del endeudamiento eXterno de Rusia}

En cuanto a la dinámica del endeudamiento externo de Rusia durante el periodo de 1993 a 2014, tuvo una tendencia ascendente; como consecuencia, la deuda externa rusa creció de 117900 millones de dólares a finales de 1993 a 728900 millones a finales de 2013. Según los datos del Banco de Rusia, a finales de diciembre de 2014 la deuda bajó a 597300 millones de dólares. En otras palabras, durante el periodo analizado el aumento del endeudamiento externo de Rusia fue de 479400 millones, o sea de 5.1 veces.

Como se observa en el cuadro 1, el monto de la deuda de la exURSS en la deuda total de Rusia bajó de 104500 millones de dólares en 1993 a 10200 millones en 2014. Su peso disminuyó de 88.6\% a $1.8 \%$ durante el periodo analizado. En otras palabras, la deuda externa heredada de la URSS dejó de jugar el principal papel en el problema del endeudamiento externo de Rusia.

Entre los factores que permitieron resolver el problema del endeudamiento heredado de la URSS es necesario mencionar los siguientes.

En primer lugar, en la década de 1990 Rusia realizó un esfuerzo enorme para restructurar la deuda soviética. En ese caso el país tenía que negociar con tres grupos de acreedores: los países agrupados en el Club de París, al cual correspondía casi la mitad de la deuda; los bancos comerciales, que formaban el Club de Londres (con una tercera parte de aquella); y las empresas del Club de Tokio. El proceso de restructuración de la deuda soviética transitó por cuatro etapas. Durante la primera, de 1993 a 1995, el Club de París ofreció varias veces el aplazamiento de 90 días para efectuar los pagos del principal. Durante la segunda etapa, de 1993 a 1995, Rusia firmó los primeros acuerdos de restructuración de la deuda de la URSS con el Club de París. En abril de 1993, éste le concedió una 
prórroga de diez años del servicio de la deuda a mediano y largo plazos (unos 15000 millones de dólares) incluido un periodo de gracia de cinco años. Como resultado, en 1993 Rusia tuvo que pagar sólo 2000 millones de dólares de los 17000 millones que estaba obligada a pagar. ${ }^{3}$ A mediados de 1994 y en junio de 1995 Rusia obtuvo del Club de París una prórroga para pagar hasta finales de cada año: los montos eran equivalentes a 7000 millones de dólares. ${ }^{4}$

\section{Cuadro 1}

La deuda externa de Rusia en 1993-2014, en miles de millones de dólares

\begin{tabular}{|l|r|r|r|r|r|r|r|r|r|r|}
\hline & 1993 & 1998 & 2001 & 2004 & 2005 & 2006 & 2008 & 2011 & 2013 & 2014 \\
\hline Total & $\mathbf{1 1 7 . 9}$ & $\mathbf{1 8 8 . 4}$ & $\mathbf{1 4 6 . 3}$ & $\mathbf{2 1 3 . 5}$ & $\mathbf{2 5 7 . 2}$ & $\mathbf{3 1 3 . 2}$ & $\mathbf{4 8 0 . 5}$ & $\mathbf{5 4 5 . 2}$ & $\mathbf{7 2 8 . 9}$ & $\mathbf{5 9 7 . 3}$ \\
\hline La deuda de la ex URSS & 104.5 & 98.2 & 78.4 & 74.5 & 53.3 & 28.7 & 19.7 & 18.0 & 14.4 & 10.2 \\
\hline La deuda de Rusia & 13.4 & 90.2 & 67.9 & 139.0 & 203.9 & 284.5 & 460.8 & 527.2 & 714.5 & 587.1 \\
\hline \multicolumn{8}{|c|}{ En porcentaje } \\
\hline Total & $\mathbf{1 0 0 . 0}$ & $\mathbf{1 0 0 . 0}$ & $\mathbf{1 0 0 . 0}$ & $\mathbf{1 0 0 . 0}$ & $\mathbf{1 0 0 . 0}$ & $\mathbf{1 0 0 . 0}$ & $\mathbf{1 0 0 . 0}$ & $\mathbf{1 0 0 . 0}$ & $\mathbf{1 0 0 . 0}$ & $\mathbf{1 0 0 . 0}$ \\
\hline La deuda de la ex URSS & 88.6 & 52.1 & 53.6 & 34.9 & 20.7 & 9.2 & 4.1 & 3.3 & 2.0 & 1.8 \\
\hline La deuda de Rusia & 11.4 & 47.9 & 46.4 & 65.6 & 79.3 & 90.8 & 95.9 & 96.7 & 98.0 & 98.2 \\
\hline
\end{tabular}

A partir de 2001 en la deuda externa de la ex URSS están incluidos los eurobonos, emitidos tras la restructuración del endeudamiento de la ex-urss ante el Club de Londres. En la estadística oficial los eurobonos forman parte de la nueva deuda externa de Rusia.

Fuente: Calculado con base en los datos del Banco de Rusia

Teniendo en cuenta que la situación económica de Rusia no mostraba síntomas de mejoramiento, en la tercera etapa se buscó la restructuración de largo plazo con los clubes de París y de Londres, propuesta por el presidente ruso B. Yeltsin en junio de 1995. Sin embargo, fue hasta abril de 1996 cuando el Club de París aceptó reestructurar unos 38000 millones de dólares de la deuda. Según el acuerdo, los reembolsos se distribuirían a lo largo de 25

${ }^{3}$ V. Semenov, "Vneshniaya zadolzhennost Rossii i latinoamerikanskiy opyt", ME i MO, núm 5, 1994, p.31.

${ }^{4}$ Finansovye Izvestia, núm. 89, 17 de noviembre de 1995. 
años y Rusia obtendría un plazo de gracia para empezar a reembolsar el capital de los préstamos contraídos hasta 2002, por lo que durante 1996 Moscú sólo tenía que pagar aproximadamente 2000 millones de dólares, en lugar de los 8000 millones que de otra manera hubiera tenido que erogar. ${ }^{5}$

Por otra parte, Rusia empezó la negociación de restructuración de su deuda equivalente a 28000 millones de dólares con el Club de Londres. Tras la firma de acuerdo a finales de 1997, el monto de la deuda era de 22500 millones de dólares por concepto del principal, más 6000 millones por intereses. Se recurrió al método de convertir la deuda en títulos, práctica internacional generalizada. El Vnesheconombank, el representante de Rusia en las negociaciones, emitió los títulos PRIN (Principal Loan) por valor del principal y los IAN (Interest Accrual Notes) por valor de intereses acumulados, los cuales tendrían que rembolsarse en 2020 y 2015, respectivamente. Se registraron en la bolsa de Luxemburgo y circulan tanto en el mercado de valores de Rusia como en el internacional.

Gracias a los acuerdos firmados con los clubes de París y Londres, Rusia logró reestructurar 67300 millones de dólares, equivalentes a $70 \%$ de la deuda externa de la Unión Soviética.

La cuarta etapa de la restructuración comenzó en agosto de 1998, cuando se presentó la profunda crisis financiera que llevó a la devaluación de la moneda nacional, lo cual imposibilitó el cumplimiento de las obligaciones del servicio de la deuda externa. En esas condiciones Rusia recurrió al Club de París para solicitar una restructuración adicional y en agosto de 1999 se firmó el memorando que establecía que en ese año y el siguiente Rusia tenía que pagar 8100 millones de dólares de los 40000 millones que representaban sus obligaciones ante esa organización. ${ }^{6}$

Más tarde, en febrero de 2000, Rusia firmó un acuerdo con el Club de Londres para la quita de $36.5 \%$ del valor del principal (obligaciones PRIN) y de $33 \%$ del valor de los intereses acumulados. La deuda restante se transformó en los llamados eurobonos por 21000 millones de dólares. Es decir, se emitieron dos tramos uno por

${ }^{5}$ Finansovye Izvestia, núm. 47, 30 de abril de 1996.

${ }^{6}$ R. Zimenkov, Rossiya: integratsiya v mirovuyu ekonomiku, Moscú, 2002, p. 109. 
2800 millones de dólares, que deberían pagarse en 2010, y otro por 18200 millones por liquidarse en 2030. A partir de esa fecha el Vnesheconombank transfirió la responsabilidad de la deuda soviética, ante el Club de Londres, al gobierno de Rusia.

Es importante señalar que este último pacto tuvo una gran trascendencia para el mejoramiento de la posición del país en el mercado mundial de capital de préstamo; contribuyó al aumento de la calificación crediticia de Rusia y su salida al mercado de eurodólares en 2001-2002.

En 1998 Rusia llegó a un acuerdo con los acreedores para restructurar la deuda comercial soviética con el modelo empleado con el Club de Londres. Se previó anular cerca de la tercera parte de la deuda y transformar el resto en euroobligaciones. Lo anterior fue pactado en 2001. En segundo lugar, el crecimiento económico que Rusia ha experimentado desde 2000 hasta el inicio de la crisis económico-financiera mundial de 2009, así como el aumento de los ingresos por concepto de exportación, debido al aumento de los precios de hidrocarburos en los mercados internacionales, que trajo el crecimiento de las reservas en moneda extranjera, permitieron a ese país euroasiático no solamente seguir solventando sin ningún problema pagos por concepto del servicio de su deuda externa, sino también tomar la decisión de un reembolso anticipado de la deuda externa del país, ante todo de su deuda con el Club de París, la cual constituía la parte fundamental de la deuda externa rusa. Las negociaciones entre Rusia y el Club de París iniciaron en septiembre de 2004 y concluyeron con la firma en mayo de 2005 del acuerdo sobre la cancelación de la deuda rusa por valor de 15000 millones de dólares, 6500 millones de la cual correspondió a Alemania. Es interesante mencionar que la parte de ese país en la deuda total de Rusia ante el Club de París fue de $46 \%$.

De acuerdo con los cálculos del Ministerio de desarrollo económico y de comercio de Rusia, la cancelación de esa parte del endeudamiento de Rusia con el Club de París le permitiría ahorrar 6000 millones de dólares por concepto de pago de los intereses. ${ }^{7}$

7 A. Lijachov: "Vneshniaya zadolzhennost i dolgovaya diplomatiya Rossii v perejodniy period”, Vneshneekonomicheskiy Bulleten, núm. 10, 2005, p. 26. 
En 2005, Rusia logró también cancelar su deuda con el FMI, y se convirtió en su miembro en junio de 1992.

En junio de 2006 entre el Club de París y Rusia fue firmado otro acuerdo, según el cual se logró la cancelación de unos 22000 millones de dólares de deuda rusa restante. A diferencia del acuerdo logrado en 2005, ahora Rusia se comprometía a pagar un premio a sus principales acreedores por valor de mil millones de dólares, $70 \%$ del cual correspondió a Alemania y el restante $30 \%$ se dividía entre Francia, Gran Bretaña y Dinamarca. ${ }^{8}$

La cancelación de deuda externa ante los países miembros del Club de París fue de suma importancia para Rusia. Por una parte, el pago anticipado de la deuda permitía a Rusia ahorrar 7000 millones de dólares por concepto de pago de intereses solamente en 2006. Por la otra, se disminuía considerablemente la carga de la deuda externa rusa para la economía nacional. Así, de acuerdo con los expertos del Ministerio de Finanzas de Rusia, tal índice importante, que determina el nivel de endeudamiento externo, como el del valor actual de la deuda externa como porcentaje del PIв nacional, disminuyó de $96 \%$ del PIB en 1999 a $9 \%$ a finales de 2006. ${ }^{9}$ Lo último contribuía al aumento del ranking de Rusia por las agencias internacionales, lo que a su vez podría mejorar el clima para inversión en el país.

Los datos presentados en el cuadro 1 permiten también afirmar que desde 1993 a 2013 la deuda rusa después de la desintegración de la URSS creció de 13400 millones de dólares a 714500 millones. Para finales de 2014, la misma bajó a 587100 millones de dólares. En otras palabras, durante el periodo analizado el aumento del endeudamiento externo de Rusia fue de 573700 millones, o sea de casi 44 veces. Su peso en la deuda total de Rusia aumentó de $11.4 \%$ a $98.2 \%$.

En cuanto a los riesgos del endeudamiento externo de Rusia para la economía nacional, como se observa en el cuadro 2, en 2014 el índice de la deuda externa como porcentaje del pIB y el de la deuda externa como porcentaje de las exportaciones de mer-

\footnotetext{
${ }^{8}$ Rossiyskaya Gazeta, 1 de julio de 2006.

${ }^{9}$ Rossiyskaya Gazeta, 25 de agosto de 2006.
} 


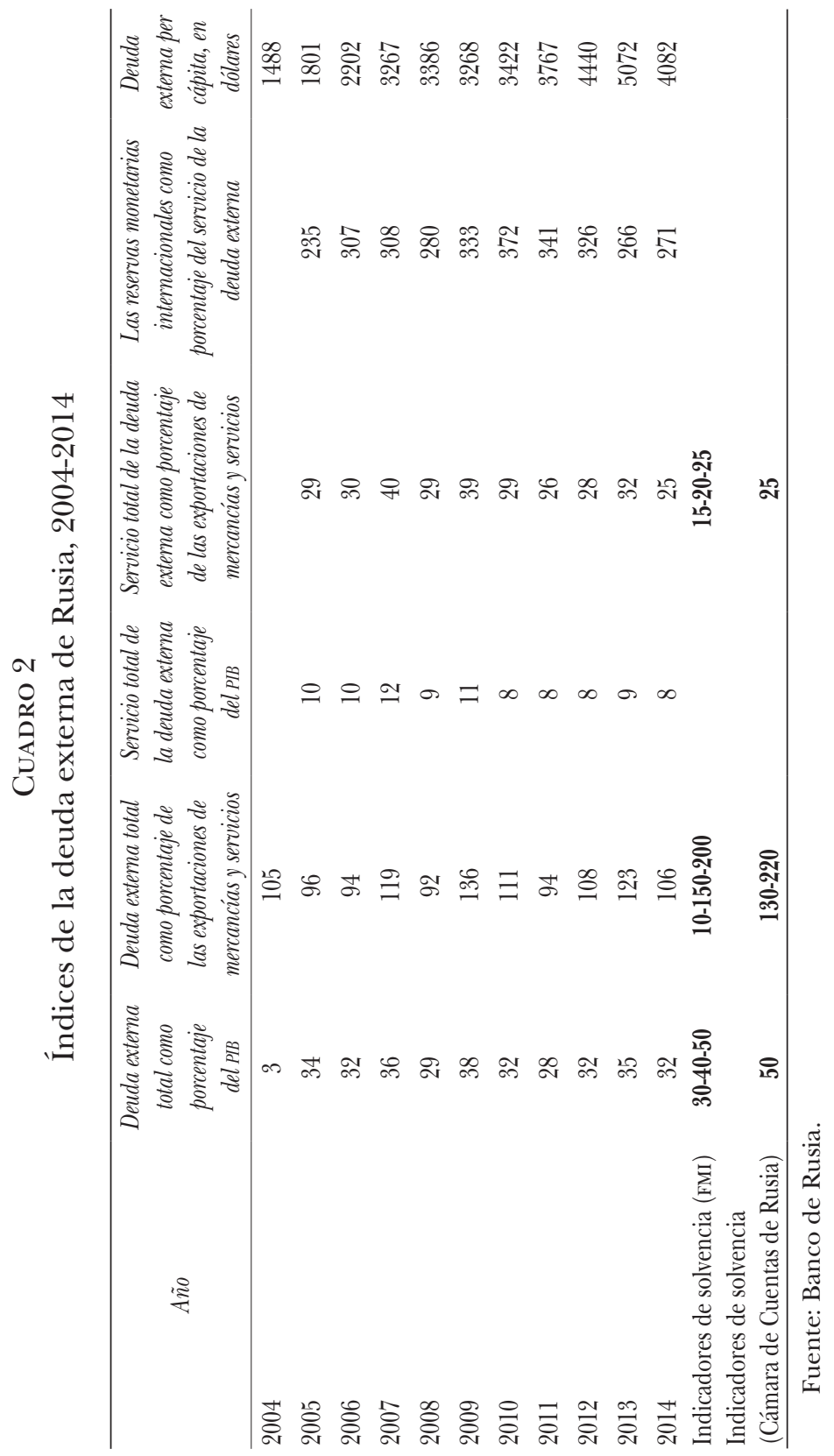


cancías y servicios se encontraba entre el nivel bajo y mediano de riesgo. El índice del servicio de la deuda externa como porcentaje de las exportaciones de mercancías y servicios representaba el nivel alto de riesgo. Se observa también el crecimiento del endeudamiento externo por habitante, que aumentó de 1488 dólares en 2004 a 5072 a finales de 2013, si bien bajó a 4082 en 2014 .

Estructura DE LA DEUdA EXTERNA DE RUSiA

Antes de analizar la estructura de la deuda externa de Rusia, es necesario aclarar que hasta 2006 el Banco de Rusia dividía la misma en la deuda pública externa y la deuda privada externa. La primera incluía la deuda externa heredada de la URSS, la deuda de los órganos de administración estatal y del Banco de Rusia. El endeudamiento de los bancos y empresas rusas se consideraba como la deuda privada externa.

De acuerdo con esa metodología, desde 1993 hasta 2008 tuvo lugar la disminución de la deuda pública externa, lo que se explica por la restructuración de la deuda heredada de la URSS y el pago anticipado de la misma. Como consecuencia, su peso en la deuda externa total del país bajó de 98.1 a 6.7\%. Sin embargo, a partir de 2011 se observa el aumento de la deuda pública externa de Rusia. Lo último se debe a la emisión de valores en rublos, ante todo de los bonos de préstamos federales por el Ministerio de Finanzas de Rusia. Como resultado, el peso de la deuda pública externa creció hasta $10.7 \%$ a finales de 2013. Sin embargo, a consecuencia de la disminución de la misma a partir del último trimestre de $2013 \mathrm{su}$ peso bajó a $8.7 \%$ a finales de 2014. De acuerdo con los expertos rusos, la disminución de la deuda pública externa se ha convertido en una de las manifestaciones del estancamiento de la economía nacional. En 2014 un papel importante en ese proceso ha jugado la introducción de las sanciones por los países de Occidente. ${ }^{10}$

${ }^{10}$ A. Shabalin, "Dinamika gosudarstvennogo I korporativnogo dolga Rossii v usloviyaj ekonomicheskij sanktsiy", Vestnik instituta ekonomiki RAN, núm. 2, 2015, p.117. 
No obstante, la tendencia más pronunciada en el periodo analizado fue la del aumento considerable de la deuda privada externa, cuyo peso pasó de $1.9 \%$ en 1993 a $91.3 \%$ en $2014 .{ }^{11}$ La mayor parte de la misma correspondió al endeudamiento de las empresas no financieras.

Es necesario aclarar que en la deuda privada externa se incluía tanto la deuda de los bancos y empresas privadas, como la de los bancos y empresas con participación estatal. Lo último distorsionaba la estructura real del endeudamiento externo de Rusia. Con el objetivo de corregir esa situación, a partir de 2006 en las estadísticas de la deuda externa de Rusia se introdujo una nueva categoría, o sea la deuda externa del sector público en la definición ampliada que incluye el endeudamiento de los bancos y empresas con participación estatal. La última se descontaba de la deuda privada externa del país.

\section{Cuadro 3}

La estructura de la deuda externa de Rusia, 1993-2014, en miles de millones de dólares

\begin{tabular}{lrrrrrrr}
\hline & 1993 & 2001 & 2005 & 2008 & 2011 & 2013 & 2014 \\
\hline Total & $\mathbf{1 1 7 . 9}$ & $\mathbf{1 4 6 . 3}$ & $\mathbf{2 5 7 . 2}$ & $\mathbf{4 8 0 . 5}$ & $\mathbf{5 4 5 . 2}$ & $\mathbf{7 2 8 . 9}$ & $\mathbf{5 9 7 . 3}$ \\
La deuda pública externa & $\mathbf{1 1 5 . 7}$ & $\mathbf{1 1 1 . 1}$ & $\mathbf{8 2 . 0}$ & $\mathbf{3 2 . 3}$ & $\mathbf{4 4 . 4}$ & $\mathbf{7 7 . 6}$ & $\mathbf{5 2 . 2}$ \\
Loa órganos de administración estatal & 111.8 & 103.0 & 71.1 & 29.5 & 33.2 & 61.7 & 41.6 \\
La deuda de la URSS & 104.5 & 78.4 & 53.3 & 19.7 & 18.1 & 14.4 & 10.2 \\
La deuda del Banco de Rusia & 3.9 & 8.1 & 10.9 & 2.8 & 11.2 & 15.9 & 10.6 \\
La deuda privada externa & $\mathbf{2 . 2}$ & $\mathbf{3 5 . 2}$ & $\mathbf{1 7 5 . 0}$ & 448.3 & $\mathbf{5 0 0 . 8}$ & $\mathbf{6 5 1 . 2}$ & $\mathbf{5 4 5 . 1}$ \\
La deuda de los bancos & 1.3 & 11.3 & 50.0 & 166.3 & 162.9 & 214.4 & $\mathbf{1 7 1 . 5}$ \\
La deuda de las empresas no & & & & & & & \\
financieras & 0.9 & 23.9 & 124.9 & 282.0 & 337.9 & 463.8 & 373.6 \\
\hline
\end{tabular}

Fuente: Los datos del Banco de Rusia.

La nueva metodología adoptada en 2006 por el Banco de Rusia para el análisis de la deuda externa de Rusia cambia cardinalmente

${ }^{11}$ Calculado con base en el cuadro 3 . 
su estructura. Los datos presentados en el cuadro 4 permiten hacer las siguientes conclusiones.

Primero, desde 2006 hasta finales de 2013, la deuda pública externa creció desde 137100 millones de dólares a 375900 millones, o sea en 2.7 veces. Su peso en la deuda externa total de Rusia aumentó de 43.8 a 51.6\%. A principios de 2015, la misma bajó a 303900 millones de dólares y su peso en la deuda total de Rusia fue de $50.9 \%$.

\section{CUADro 4}

La nueva estructura de la deuda externa de Rusia, 2006-2014, en miles de millones de dólares

\begin{tabular}{lrrrrr}
\hline & 2006 & 2008 & 2011 & 2013 & 2014 \\
\hline Total & $\mathbf{3 1 3 . 2}$ & $\mathbf{4 8 0 . 5}$ & $\mathbf{5 4 5 . 2}$ & $\mathbf{7 2 8 . 9}$ & $\mathbf{5 9 7 . 3}$ \\
$\begin{array}{lrrr}\text { La deuda externa del sector público en la } \\
\text { definición ampliada }\end{array}$ & & & & \\
Los órganos de administración estatal & $\mathbf{1 3 7 . 1}$ & $\mathbf{1 6 3 . 4}$ & $\mathbf{2 2 0 . 4}$ & $\mathbf{3 7 5 . 9}$ & $\mathbf{3 0 3 . 9}$ \\
La deuda del Banco de Rusia & 44.7 & 29.5 & 33.2 & 61.7 & 41.6 \\
La deuda de los bancos con participación estatal & 3.9 & 2.8 & 11.2 & 15.9 & 10.6 \\
A deuda de las empresas con participación & 41.4 & 61.7 & 73.2 & 133.0 & 107.0 \\
$\quad$ & & & & & \\
$\quad$ estatal & 47.1 & 69.5 & 102.8 & 165.2 & 144.6 \\
La deuda privada externa & $\mathbf{1 7 6 . 1}$ & $\mathbf{3 1 7 . 1}$ & $\mathbf{3 2 4 . 7}$ & $\mathbf{3 5 3 . 0}$ & $\mathbf{2 9 3 . 4}$ \\
La deuda de los bancos & 59.8 & 104.6 & 89.6 & 81.4 & 64.4 \\
La deuda de las empresas no financieras & 116.3 & 212.2 & 235.1 & 271.6 & 229.0 \\
\multicolumn{1}{c}{ En porcentaje } & & & & \\
Total & $\mathbf{1 0 0 . 0}$ & $\mathbf{1 0 0 . 0}$ & $\mathbf{1 0 0 . 0}$ & $\mathbf{1 0 0 . 0}$ & $\mathbf{1 0 0 . 0}$ \\
La deuda externa del sector público en la & & & & & \\
definición ampliada & 43.8 & 34.0 & 40.4 & 51.6 & 50.9 \\
La deuda privada externa & 56.2 & 66.0 & 59.6 & 48.4 & 49.1 \\
\hline
\end{tabular}

Fuente: Los datos del Banco de Rusia.

Segundo, su crecimiento se explica, ante todo, por el crecimiento del endeudamiento externo de los bancos y empresas con participación del capital estatal. El último aumentó desde 88500 millones en 2006 a 298200 millones en 2013, o sea en 3.4 veces. 
Durante el periodo analizado, su peso en la deuda pública externa de Rusia pasó de $64.6 \%$ en 2006 a $79.3 \%$ en 2013. A finales de 2014, su monto descendió a 251600 millones de dólares y su peso fue de $82.8 \%$.

Tercero, en cuanto al endeudamiento del sector privado, ése aumentó 1.7 veces en el periodo analizado. Su peso en la deuda externa total de Rusia bajó de 56.2 a 49.1\%. De esa manera su contribución al aumento de la deuda externa total de Rusia era más modesta en comparación con la del sector público.

Cuarto, el valor de la deuda externa corporativa, que incluye tanto el endeudamiento externa de las empresas y bancos privados, como el de los con participación estatal, aumentó de 264600 millones de dólares en 2006 a 651500 millones en 2013, o sea en 2.5 veces. Su peso en la deuda externa total de Rusia pasó de 84.5 a $89.4 \%$ durante el periodo analizado. Sin embargo, en 2014 su monto disminuyó a 545000 millones de dólares. Su peso en la deuda externa total de Rusia fue de $91.2 \%$. El peso de la deuda de los bancos y empresas con participación estatal en la deuda corporativa total aumentó de $33.4 \%$ en 2006 a $46.2 \%$ en $2014 .^{12}$

A finales de 2013, la deuda externa corporativa de Rusia constituyó el 31.6\% del PIв nacional. Sin embargo, a finales de 2014 ese índice creció a $43 \% .{ }^{13}$ Ese aumento se explica por el hecho de que durante 2014 el tipo de cambio de dólar aumentó más de 50\%, mientras que el PIB ruso creció tan sólo $0.6 \% .{ }^{14}$ Lo dicho anteriormente significa que a pesar de la disminución del monto de la deuda externa corporativa de Rusia la profundidad del problema sigue incrementándose.

Todo lo dicho anteriormente permite concluir que actualmente la así llamada deuda externa corporativa, la cual incluye el endeudamiento de los bancos y empresas tanto privados como estatales se convierte en el eslabón más débil del endeudamiento externo ruso. Así, el reconocido economista ruso A. Aganbeguián

12 Calculado con base en el cuadro 4.

13 A. Shabalin, "Dinamika gosudarstvennogo I korporativnogo dolga Rossii v usloviyaj ekonomicheskij sanktsiy”, Vestnik instituta ekonomiki RAN, núm. 2, 2015, p. 121.

${ }^{14}$ http://www.gks.ru 
considera que la deuda externa corporativa de Rusia se ha convertido en una soga alrededor del cuello de la economía nacional. ${ }^{15}$

LA DEUDA EXTERNA CORPORATIVA Y LOS RIESGOS PARA LA ECONOMÍA NAGIONAL EN LAS CONDICIONES DE LAS SANCIONES ANTIRRUSAS

Entre las causas del crecimiento de la deuda corporativa de Rusia es necesario mencionar las siguientes.

Primero, el rasgo específico del sector bancario ruso consiste en que en los activos y pasivos de los bancos rusos predomina el dinero "corto". Debido a eso los bancos rusos no disponen de suficientes recursos para ofrecer créditos a largo plazo a las empresas nacionales. Por lo tanto, no pueden jugar el papel crucial en la canalización de los flujos financieros de la economía.

Segundo, en Rusia no existen grandes fondos de inversión, grandes fondos de pensiones privados ni grandes compañías aseguradoras, o sea intermediarios financieros no bancarios. Lo anterior explica el desarrollo precario de los mercados financieros y por lo tanto el papel insignificante de los intermediarios financieros no bancarios como proveedores de financiación a largo plazo.

Tercero, en Rusia la tasa de interés de los préstamos ofrecidos por los bancos nacionales a las empresas es de dos a tres veces mayor que la de los bancos de los países de Occidente. Por ejemplo, en agosto de 2014 la tasa de interés media ponderada de los préstamos ofrecidos por más de tres años fue de $11.96 \% .{ }^{16}$ Lo último se explica por el hecho de que la tasa de inflación y la tasa de refinanciación del Banco de Rusia son más altas que en los países occidentales. ${ }^{17}$ Debido a eso los bancos y empresas rusas prefieren

${ }^{15}$ A. Aganbeguián, "Vozrastayushiy korporativniy dolg pered inostrannymi investorami - "petliya na shee" nazionalnoy ekonomiki”, Dengui i kredit, núm. 3, 2013, pp. 3-8.

16 http://www.cbr.ru/statistics / print.aspx?file=b_sector/rates_cr-no-r_14.ht m\&pid=procstavnew\&sid=ITM_60399

${ }^{17}$ En 2013, la tasa de inflación fue de $6.45 \%$ y la tasa de refinanciamiento del Banco de Rusia, de $8.25 \%$ a partir del 14 de septiembre de 2012. 
obtener préstamos en el extranjero en caso de realizar grandes proyectos de inversión.

Varios economistas rusos proponen sustituir los recursos financieros provenientes del exterior para financiar la economía nacional por los internos, al recurrir al empleo de una parte de las reservas internacionales, las cuales a finales de 2013 alcanzaron 509595 millones de dólares, de los cuales las reservas de divisas representaron 469600 millones de dólares. ${ }^{18}$

El crecimiento del endeudamiento externo corporativo de $\mathrm{Ru}-$ sia representa altos riesgos para la economía nacional, especialmente en las condiciones de la puesta en marcha a partir del marzo de 2014 de las sanciones económicas de los países de Occidente contra ese país euroasiático. Como se sabe, dichas sanciones se están adaptando contra Rusia en represalia por lo que calificaron como sus esfuerzos por desestabilizar Ucrania. En septiembre de 2014, Estados Unidos y la Unión Europea recrudecieron dichas sanciones al anunciar la prohibición de cualquier operación de los bancos estadounidenses y europeos con las instituciones bancarias rusas con participación estatal en instrumentos financieros con un vencimiento mayor a treinta días. Por otra parte, dichas sanciones prohíben las subastas de las obligaciones y otros valores con vencimiento de treinta días, emitidos por las empresas rusas incluidas en la lista de empresas sancionadas. Entre ellas figuran tales empresas, como Gazprom, Gazprom Neft, Lukoil, Surgutneftegaz, Rosneft, entre otras. En consecuencia, dichas sanciones cierran el acceso de las empresas y bancos rusos con participación estatal a los mercados financieros internacionales y de esa manera obstaculizan el crecimiento económico de ese país euroasiático.

En cuanto a los riesgos que las sanciones antirrusas traen para la economía rusa, es necesario mencionar los siguientes. En primer lugar, el crecimiento tan pronunciado de la deuda externa corporativa de Rusia en sí mismo trae para las empresas y bancos rusos altos riesgos porque los empuja a recurrir al endeudamiento externo para financiar el servicio de la misma. Además, la tercera parte de dicha deuda es la deuda a corto plazo, lo que complica la

${ }^{18}$ http:/ / www.cbr.ru/hd_base/default.aspx?Prtid=mrrf_m 
situación. Así, de acuerdo con el Banco de Rusia, en 2015 el servicio de la deuda externa corporativa de Rusia alcanzará 120000 millones de dólares, de los cuales 42000 millones corresponden a los bancos rusos y 77000 millones a las empresas no financieras. ${ }^{19}$ Según los cálculos de Bridgewater (el mayor fondo de alto riesgo del mundo), Rusia tiene que hacer frente a vencimientos de la deuda exterior por unos 127000 millones de euros desde agosto de 2014 a agosto de 2015, lo que implica el reto de refinanciarla con deuda a corto plazo o buscar fuentes de financiación domésticas. ${ }^{20}$

El cierre del acceso de las empresas y bancos rusos con participación estatal a los mercados financieros internacionales agrava el problema del servicio de la deuda externa rusa y por lo tanto los va a obligar a recurrir a reservas internacionales del país. De acuerdo con las estimaciones de algunos economistas rusos, las últimas podrían disminuirse en más de $60 \%$ durante los dos próximos años. Según Serguey Afontsev, el reto macroeconómico principal de la política de sanciones de Occidente contra Rusia en 2015 está relacionado con la necesidad de pagar los pasivos externos del sector empresarial, en términos de la actual falta de acceso a los mercados financieros occidentales. ${ }^{21}$

En segundo lugar, el Estado ruso ofrece un fuerte apoyo paternalista a las grandes empresas privadas. Lo anterior se manifestó con claridad en el otoño de 2008, cuando se creó un fondo especial para apoyar a aquellas empresas privadas que se enfrentaron con dificultades en cuanto al pago de su deuda externa. El valor de dicho fondo fue de 50000 millones de dólares. En las condiciones de la crisis, que se caracterizó por las dificultades de acceso al financiamiento externo, solamente el apoyo financiero del Estado les permitió sobrevivir y salvar sus activos pignorados en los bancos extranjeros. ${ }^{22}$

${ }^{19}$ http:/ / expert.ru/2015/01/20/rossiya-vsem-proschaet/

20 http://internacional.elpais.com/internacional/2014/07/30/actualidad/ 1406742919_030104.html

${ }^{21}$ S. Afontsev, "Vijod iz krizisa v usloviyaj sanktsiy: missiya nevypolnima?", Voprosy ekonomiki, núm. 4, 2015, p. 24.

22 Véase Boris Kheyfets, Globalniy dolgovoy krizis i riski dolgovoy politiki Rossii, Moscú, 2012, p. 27. 
En tercer lugar, casi la mitad de la deuda externa corporativa rusa corresponde a las empresas y bancos rusos con participación estatal, la mayor parte de la cual es de tales gigantes rusos, como Gazprom, Sberbank, Rosneft y vтв. Así, en abril de 2014, 30\% de la deuda externa de las empresas no financieras de Rusia correspondió a tan sólo cinco empresas, o sea a Rosneft, Gazprom, Transneft, RZD (Ferrocarriles rusos) y Tatneft. ${ }^{23}$ En cuanto al endeudamiento de los bancos rusos, a cuatro instituciones crediticias estatales, o sea a Sberbank, vтв, Gazprombank y Rosseljozbank les correspondió $54 \%$ de la misma. ${ }^{24}$

Es necesario subrayar que dichas empresas juegan un papel crucial en la economía rusa. En cuanto a Gazprom, monopolista ruso absoluto de producción y exportación del gas a otros países del mundo, le pertenecen $17 \%$ de las reservas mundiales del gas y $13 \%$ de su producción mundial. La dirección prioritaria de las exportaciones del gas ruso sigue siendo hasta el momento el mercado europeo. En 2013 la contribución del gigante ruso a los suministros del gas a ese continente alcanzó 30\%, el mayor comprador del gas ruso fue Alemania. ${ }^{25}$ En 2014, el peso de Gazprom en los suministros del gas a Europa bajó a 25\%.26 Sin embargo, a mediano plazo existen perspectivas alentadoras para que la importancia de los suministros del gas a Europa desde Rusia se mantuviera.

La mayor compañía petrolera rusa, Rosneft, en 2013 concentró $40 \%$ de la producción de petróleo en el país. De acuerdo con el informe anual de 2013, el peso de la empresa en las exportaciones rusas del crudo fue de $34 \% .{ }^{27}$

Teniendo en cuenta que en 2013, de acuerdo con los datos del Comité Estatal de Estadísticas de Rusia, el peso de los energéticos

${ }^{23}$ A. Shabalin, "Gosudarstvenniy i korporativniy dolg Rossii v novyj usloviyaj”, Bankovskoye delo, núm. 2, 2015, p. 46.

24 A. Shabalin, "Dinamika vneshnego golga bankov v sovremennoy Rossii", Bankovskiye uslugui, núm. 2, 2014, p. 8.

${ }^{25}$ http://www.gazprom.ru/about/today/

26 http://www.bbc.co.uk/russian/business/2015/02/150204_gazprom_europe_export_analysis

${ }^{27}$ http://www.rosneft.ru/docs/report/2013/metrics.html 
en las exportaciones de Rusia alcanzó casi $72 \%{ }^{28}$ y que los ingresos del presupuesto estatal de Rusia provenientes de las exportaciones de hidrocarburos alcanzaron $50 \%$ de los ingresos totales del mismo en 2012, ${ }^{29}$ se puede concluir que el desarrollo económico y social de Rusia en gran parte depende del desarrollo del sector energético nacional y de sus gigantes estatales, en particular.

Según las nuevas teorías del crecimiento endógeno, el sistema financiero no solamente sirve de intermediario financiero entre los ahorradores últimos de la economía y los demandantes de financiación, sino que también juega un papel relevante en el logro de mayores ritmos de crecimiento. Lo último se logra por dos vías básicamente: una es posibilitar que un mayor volumen de recursos se canalice hacia la inversión productiva, y la segunda es garantizar, mediante una adecuada selección de los demandantes de recursos, que reciban financiación aquellas actividades que generen un mayor rendimiento, con que se incremente así la productividad del capital. En cuanto a los bancos rusos con participación estatal, que son sancionados por los Estados Unidos y los países de la Unión Europea, ocupan un lugar dominante en el sistema bancario ruso. Así, Sberbank, el mayor banco en el país, controla casi $30 \%$ de los activos bancarios del país, $46.4 \%$ de los depósitos de la población, $34.7 \%$ de los créditos a las personas físicas y $33.9 \%$ de los créditos a las personas jurídicas. ${ }^{30}$ En 2013, el peso del banco vтв, el segundo banco en Rusia, en los activos bancarios es de $15.4 \%$. Le corresponde $9.3 \%$ de los depósitos de la población, $15.5 \%$ de los créditos ofrecidos a las personas jurídicas y $13.4 \%$ de los ofrecidos a las personas físicas. ${ }^{31}$

${ }^{28}$ Calculado con base en: http://www.gks.ru/wps/wcm/connect/rosstat_ma in/rosstat/ru/statistics/publications/catalog/doc_1140086922125

${ }^{29}$ L. Eder, "Nefteenergueticheskiy kompleks v ekonomike Rossii, en Mineralnye resursy Rossii”, Ekonomika i upravleniye, núm. 4, 2013, p. 50, http:/ /www.ipgg.sbr as.ru/ru/_layouts $/ 15 /$ WopiFrame.aspx?sourcedoc $=\%$ 2Fru $\% 2$ FFiles $\%$ 2Fpublicati ons \%2Fibc\%2Fmrr\%2D2013\%2D04\%2D48\%2Epdf\&action=view

${ }^{30} \mathrm{http}: / /$ www.sberbank.ru/moscow/ru/about/today/

${ }^{31}$ Informe anual del banco VTB de 2013, http:/ / www.vtb.ru/upload/iblock/ dc8/VTB\%202013_rus_25062014.pdf 
Todo lo dicho anteriormente permite concluir que los bancos rusos con participación estatal, ante todo Sberbank y vтв, son las locomotoras del sector bancario ruso y como consecuencia juegan el papel crucial en la financiación de la economía nacional.

Formalmente, el Estado no responde por las deudas de empresas con participación estatal. Pero en realidad, en situaciones críticas el Estado les ayuda a pagar sus deudas, tal como ocurrió durante la última crisis económica-financiera internacional. En aquel entonces el gobierno ruso ofreció créditos a corto y largo plazo a tales bancos con participación estatal, como Sberbank, vTB, Gazprombank, así como apoyó financieramente a las empresas Gazprom y Rosneft. Debido a lo dicho anteriormente, la deuda externa de las empresas y bancos con participación estatal la denominan la deuda cuasi-pública porque los riesgos originados por la misma corresponden al Estado.

Es necesario aclarar que las sanciones impuestas por los países de Occidente no van a tener un efecto inmediato en la economía rusa. De acuerdo con un informe publicado el 22 de octubre de 2014 por la agencia calificadora Moody's Investors Service, las compañías rusas, a pesar de las sanciones, serán capaces de cumplir con sus obligaciones de pago hasta finales de 2015. Se destaca que sólo $7 \%$ de las compañías examinadas por la agencia necesitarán la refinanciación para mantener liquidez.

Pero si se mantienen las sanciones después de 2015, la gran cantidad de compañías sufrirá el déficit de financiamiento y necesitará la ayuda del gobierno, advierte el informe. Entre posibles fuentes de financiamiento, los analistas de Moody's nombran a China, que podría reemplazar a socios occidentales en el contexto de las sanciones antirrusas. ${ }^{32}$

Consideramos que las sanciones contra Rusia van a tener un efecto retardado que va a manifestarse a mediano y largo plazo. Así, el ministro de Desarrollo Económico de Rusia, Alexéi Uliukaev, en el marco de la cumbre de la APEC, que se celebró en noviembre de 2014 en Pekín, señaló que las sanciones contra las instituciones financieras rusas son las más graves porque crean un saldo negativo

${ }^{32}$ RBC daily, 23 de octubre de 2014. 
constante, devalúan el rublo y aceleran la inflación. Uliukaev agregó que la alta inflación reduce la demanda que es el motor de la economía y al conservarse el régimen de las sanciones ese mecanismo del crecimiento económico dejará de funcionar. ${ }^{33}$ En otras palabras, indirectamente las sanciones afectan a toda la economía rusa. Aún más, su impacto se acelera a medida que pasa el tiempo.

\section{CuAdro 5}

Deudas de las mayores compañías y bancos rusos controlados por el Estado a los bancos internacionales en 2012 (miles de millones dólares)

\begin{tabular}{llcr}
\hline & \multicolumn{1}{c}{ Área } & $\begin{array}{c}\text { El peso del Estado } \\
\text { en el capital }\end{array}$ \\
\hline Gazprom & Monopolista absoluto de producción de gas & $50 \%$ & 40.4 \\
Sberbank & "Banco de ahorro", el mayor en el país & $50 \%$ & 28.1 \\
Rosneft & La mayor compañía petrolera & $75.16 \%$ & 24.7 \\
vтв & "Banco de comercio exterior", segundo en el país & $60.9 \%$ & 24.2 \\
Rosseljozbank & Banco agrícola & $100 \%$ & 17.9 \\
Gazprombank & Banco de Gazprom & & 17.0 \\
Transneft & Le pertenecen todos oleoductos del país. & $100 \%$ & 13.0 \\
RzD & "Ferrocarriles rusas" & $100 \%$ & 5.7 \\
& & $95.52 \%$ & \\
Banco de Moscú & Compañía eléctrica al que pertenecen casi todas & pertenece a vTB & 3.0 \\
& las estaciones hidroeléctricas & $58.1 \%$ & 1.3 \\
\hline
\end{tabular}

Fuente: Mijail Matovnikov, "Problemy rossiyskogo vneshnego korporativnogo dolga namnogo slozhnee, chem rfzhtnsiya”, Dengui i kredit, núm. 9, 2013, pp. 42, 46.

La aplicación de sanciones contra Rusia ha coincidido con la caída de los precios internacionales del crudo, que se ha registrado a partir de los mediados de verano de 2014. Si el 19 de junio de 2014 la cotización del petróleo Brent alcanzó 115 dólares por barril, el 27 de enero de 2015 bajó a 49.33 dólares. El 12 de mayo

${ }^{33}$ http:/ /sp.ria.ru/neighbor_relations/20141108/162946463.html 
subió a 65.8 dólares. ${ }^{34}$ Lo último ha traído consecuencias muy negativas para la economía rusa, dependiente de las exportaciones de los energéticos a los mercados internacionales. La caída en los precios del petróleo ha provocado un debilitamiento significativo del tipo de cambio del rublo, lo que da un efecto inflacionario bastante fuerte. Por su parte, una presión inflacionaria más fuerte reduce el poder adquisitivo de la población, lo que disminuye el consumo. Desde principios de 2014 a los principios de febrero de 2015, el rublo ha perdido casi $50 \%$ de su valor ante el euro y $80 \%$ ante el dólar. ${ }^{35}$ Para apoyarlo, el Banco de Rusia ha utilizado las reservas monetarias internacionales del país. De acuerdo con los datos del Banco Central de Rusia, su monto disminuyó de 509560 millones de dólares para el 1 de enero de 2014 a 385460 millones para el 1 de enero de 2015, o sea 24\%. Únicamente en diciembre de 2014 la disminución de las reservas internacionales de Rusia alcanzó 33420 millones de dólares. ${ }^{36}$ Para el 1 de marzo de 2015 su monto bajó a 360200 millones de dólares. Según el ministro de Finanzas de Rusia, Antón Siluanov, por las sanciones geopolíticas Rusia pierde al año 40000 millones de dólares y otros 90000-100 000 millones anuales por el descenso de un $30 \%$ del precio de petróleo. ${ }^{37}$

Sin embargo, es importante señalar que desde finales de marzo de 2015 tiene lugar la recuperación del valor del rublo, lo que se debe en gran parte a la estabilización de los precios de petróleo y la disminución de la salida de los capitales al extranjero. Lo último se explica por el hecho de que para marzo de 2015 los pagos máximos de la deuda externa rusa ya han pasado.

Por otra parte, de acuerdo con el Ministerio de Economía de Rusia, las sanciones impuestas a Moscú por su intervención en la crisis de Ucrania y el desplome en los precios del petróleo habrán llevado a la economía rusa a recesión 2015. A principios de diciembre de 2014 el Ministerio de Economía cambió a la baja la previsión

${ }^{34}$ http://cincodias.com/mercados/materias_primas/petroleo_brent/1/his torico/36

${ }^{35}$ Calculado con base en: Banco de Risia, http:/ /www.cbr.ru/currency_base/ daily.aspx

36 http:/ / www.cbr.ru/hd_base/default.aspx?Prtid=mrrf_m

${ }^{37}$ http://top.rbc.ru/finances/24/11/2014/5472ededcbb20f50f1970522 
del crecimiento económico de Rusia. Según los cálculos del ministerio, la economía nacional se contraerá $0.8 \%$, lejos de la previsión anterior que auguraba un crecimiento de $1.2 \%$ del PIB. ${ }^{38}$ Las estimaciones del FMI son aún más pesimistas. En el estudio denominado "Las perspectivas de la economía mundial", publicado en enero de 2015, esa institución financiera estimó que el PIB ruso se habrá contraído $3 \%$ en 2015 y $1 \%$ en 2016. Lo anterior sucede por el impacto económico de la fuerte caída de los precios del petróleo y por el recrudecimiento de las tensiones geopolíticas, tanto a través de efectos directos como del impacto en la confianza. ${ }^{39}$ Las previsiones del desenvolvimiento de la economía rusa en 2015 y 2016 de la edición de dicho estudio publicado en abril de 2015 son todavía más desalentadoras. Se estima que el PIB ruso contraerá un 3.8\% en 2015 y $1.1 \%$ en 2016. Los precios bajos de las materias primas y derrames desde Rusia (a través del comercio, inversión extranjera directa y sobre todo de las remesas) desalientan también las perspectivas, particularmente a la luz de vulnerabilidades estructurales existentes. ${ }^{40}$

De acuerdo con algunos economistas rusos, aunque las causas de la crisis económica en Rusia no están relacionados con los factores geopolíticos, las sanciones impuestas por Occidente y sus consecuencias influyen directamente en la capacidad del gobierno de adoptar medidas anti-crisis. ${ }^{41}$

Por otra parte, en el país crece la inflación. De acuerdo con los datos del Comité Estatal de Estadísticas de Rusia, en 2014 su índice fue de $11.4 \%$, aunque las previsiones han sido de $6.5 \% .{ }^{42}$ En enerofebrero de 2015 el índice de los precios al consumidor alcanzó

${ }^{38}$ http://top.rbc.ru/economics/26/12/2014/549631bf9a7947c0ac478ddf

${ }^{39}$ Perspectivas de la economía mundial. FMI, enero de 2015, pp. 3-4, http:/ / www.imf.org/external/spanish/pubs/ft/weo/2015/update/01/pdf/0115s.pdf

${ }^{40}$ World Economic Outlook (wEO), Uneven Growth: Short- and Long-Term Factors, FMI, abril de 2015, pp. 2, 15, http://www.imf.org/external/pubs/ft/ weo/2015/01/pdf/text.pdf

${ }^{41} \mathrm{~S}$. Afontsev, "Vijod iz krizisa v usloviyaj sanktsiy: missiya nevypolnima?", Voprosy ekonomiki, núm. 4, 2015, p. 21.

42 http://www.gks.ru/free_doc/new_site/prices/potr/tab-potr1.htm 
$15.7 \%$ en comparación con el mismo periodo del año anterior. ${ }^{43}$ Eso quiere decir que en Rusia ha surgido el fenómeno denominado la estanflación. La disminución de las inversiones en la economía nacional a partir de 2013 empeora aún más la situación económica de ese país. Los expertos rusos afirman que la desinversión es la que determina que el periodo de recesión podría durar varios años. ${ }^{44}$

Además, las sanciones reducen la credibilidad de Rusia, lo que afecta negativamente el clima de negocios en ese país. Lo último va a originar la disminución de la afluencia de las inversiones extranjeras a la economía rusa, por una parte, y el aumento de la salida del capital al extranjero, por la otra. Las estadísticas del Banco de Rusia demuestran que durante 2014 la inversión extranjera directa en el sector no bancario de la economía rusa registró su mínimo histórico desde 2005, al constituir 16600 millones de dólares, 3.6 veces menos que en 2013. ${ }^{45}$ Por otra parte, la salida neta del capital alcanzó 151500 millones de dólares, o sea casi 2.5 veces más que en 2013. ${ }^{46}$ La gran parte de la salida del capital se explica por el pago de la deuda externa en la condiciones de la imposibilidad de las empresas rusas de refinanciarla en mercados internacionales del capital. De acuerdo con muchos expertos rusos, las sanciones de Occidente que cerraron para las empresas y bancos rusos el acceso a los mercados internaciones de capital constituyen la causa fundamental de la salida masiva del capital al extranjero. Como resultado la deuda externa del país bajó de 728900 millones de dólares a finales de 2013 a 599500 millones a finales de 2014, o sea $18 \% .{ }^{47}$ En cuanto a la aportación de la población rusa a la salida del capital del país como resultado del cambio masivo de rublo por moneda extranjera, ésa se considera mínima y se estima entre los 10000 y 20000 millones de dólares en 2014.

${ }^{43}$ http://www.gks.ru/bgd/free/b04_03/IssWWW.exe/Stg/d05/42.htm

${ }^{44}$ A. Aganbeguián, "Shest shagov, neobjodimyj dlia vozobnovleniya ekonomicheskogo rosta i dlia preodoleniya stagfliatsii, rezesii i stagfliatsii”, Dengui $i$ kredit, núm. 2, 2015, p. 8.

${ }^{45}$ http:/ / www.cbr.ru/statistics /?PrtId=svs

${ }^{46}$ http:/ / expert.ru/2015/01/20/rossiya-vsem-proschaet/

${ }^{47}$ http://www.cbr.ru/statistics/print.aspx?file=credit_statistics/debt_est_new. htm\&pid=svs\&sid=itm_43952 
Es obvio que la salida del capital no solamente mina las posibilidades del sector empresarial de invertir en la economía nacional, lo que dificulta la recuperación económica, sino que influye negativamente en el tipo de cambio de la moneda nacional y las reservas internacionales del país.

El empeoramiento del clima inversor en Rusia en 2014 condicionó también la reducción de los indicadores de la actividad de los emitentes rusos. Así, el volumen de fusiones y adquisiciones de las empresas rusas por las compañías extranjeras, según la compañía Dealogic, bajó tres veces en 2014 en comparación con el año anterior y alcanzó tan sólo 3200 millones de dólares. Por otra parte, las compañías rusas obtuvieron préstamos sindicados por valor de 11700 millones de dólares, o sea cuatro veces menos que en 2013. Bajó drásticamente la actividad de las empresas rusas en el mercado de capital propio. Así, en 2014, el valor de la oferta pública oficial realizada por las empresas rusas fue de 1890 millones de dólares. Es interesante mencionar que en 2013 la misma alcanzó 10250 millones de dólares. ${ }^{48}$

Por otra parte, la reducción en el ranking nacional de Rusia hasta el nivel "basura" por las principales agencias de calificación lleva al encarecimiento de los créditos internacionales, lo que a su vez dificulta más el acceso de las empresas y bancos rusos al mercado de capital.

Consideramos que la coincidencia en el tiempo de la introducción de las sanciones antirrusas con la disminución de la demanda del petróleo por los principales consumidores del mismo y la subsiguiente caída de los precios internacionales del crudo son los factores que se convirtieron en el gatillo de la crisis económica por la cual atraviesa actualmente la economía rusa. Al mismo tiempo, es necesario subrayar que las sanciones económicas de los países de Occidente contra Rusia se han dirigido contra los puntos más débiles de la economía nacional. Entre los últimos se encuentra la alta dependencia de las empresas y bancos rusos, incluidos los gigantes estatales, del financiamiento exterior. Por otra parte, las sanciones dirigidas contra las empresas energéticas estatales obs- 
taculizan el desarrollo de la industria petrolera y de gas rusa, el motor del crecimiento económico de ese país. Así, en agosto de 2014, se prohibió la venta de las llamadas tecnologías sensibles, incluyendo las plataformas de perforación, componentes para la perforación horizontal, equipos submarinos, equipos marinos para trabajar en el Ártico, el software para el fracturamiento hidráulico, en caso de su empleo en los proyectos en aguas profundas, árticas o de producción de aceite de esquisto bituminoso.

En septiembre de 2014, Estados Unidos prohibió la venta a las cinco empresas rusas, tales como Gazprom, Gazprom Neft, LUKoIL, Rosneft y Surgutneftegaz, de cualquier tipo de bienes, tecnología y servicios (que no fuera financiera) si se van a utilizar en el Ártico, los proyectos de aguas profundas o de pizarra bituminosa. De hecho, se han congelado todos los proyectos de las empresas rusas con sus socios estadounidenses en el desarrollo de las reservas de petróleo y gas en la plataforma del Ártico, así como los proyectos del desarrollo de las reservas de petróleo y gas difíciles de extraer en Siberia occidental.

Sin embargo, las causas fundamentales de dicha crisis se encuentran dentro de la economía de ese país. Desde nuestro punto de vista, es el agotamiento del modelo de crecimiento basado en el desarrollo del sector energético. En otras palabras, la alta dependencia de la economía de Rusia de la producción y exportaciones de los hidrocarburos fue lo que llevó a la economía rusa a la crisis actual.

Para hacer frente a los problemas económicos actuales y salvar la economía nacional, el Gobierno de Rusia aprobó a finales de enero de 2015 el plan anticrisis, cuyo costo sería de unos 2300 millones de rublos. La mayor parte de este dinero se empleará en el saneamiento de las empresas estratégicas, la capitalización de grandes bancos, el apoyo a la agricultura y al sector de la construcción, los programas de sustitución de importaciones, así como el apoyo de la población. Los fondos se sacarán del presupuesto federal y del Fondo de Bienestar Nacional (un fondo de ingresos obtenidos en la industria petrolífera rusa). ${ }^{49}$

49 http:/ / www.aif.ru/dontknows/actual/antikrizisnyi_plan_pravitelstva_Rossii_na_2015-2016_gody 


\section{COMENTARIOS FINALES}

El estado inmaduro del desarrollo del sector bancario de Rusia y como consecuencia su imposibilidad de financiar la economía nacional y la carestía de los fondos internos originó el crecimiento desmesurado del endeudamiento externo tanto de los bancos rusos como de las compañías no financieras de ese país euroasiático. En esas condiciones, los últimos se han visto obligados a recurrir al financiamiento externo, con el objetivo de seguir apoyando el desenvolvimiento de los proyectos de desarrollo. Sin embargo, los altos precios internacionales del petróleo, producto principal de las exportaciones rusas y fuente fundamental de los ingresos del presupuesto estatal, así como la estabilidad de la moneda nacional, no parecían indicar ningún problema para la economía nacional.

El conflicto en Ucrania y la aplicación en 2014 de las sanciones de los países de Occidente contra Rusia cambiaron radicalmente la situación en torno a su endeudamiento externo. Resulta que dichas sanciones han aislado a los bancos y empresas rusas del financiamiento externo y les han cortado las fuentes de financiamiento europeo y estadounidense. Lo anterior no solamente dificulta el refinanciamiento de la deuda contraída por las compañías rusas anteriormente, sino que se ha convertido en un freno muy poderoso para el desarrollo económico de Rusia. Privados de las fuentes de financiamiento internacionales, a los bancos rusos les resulta difícil prestar a las empresas locales. Lo último se ha convertido en un obstáculo para el desarrollo económico de ese país euroasiático. Debido a eso, la capitalización de los bancos rusos se convierte en una tarea primordial del gobierno de ese país.

Por otra parte, la prohibición de la venta de la tecnología occidental a las empresas energéticas rusas con participación estatal crea dificultades bastante serias para el desarrollo del sector estratégico de la economía rusa que genera la mayor parte de divisas extranjeras y cuya aportación al presupuesto estatal es de fundamental importancia. La situación se agrava por la caída de los precios internacionales del petróleo y la subsiguiente devaluación del rublo, que lleva a la disminución del poder adquisitivo de la población 
y como consecuencia a la disminución de la demanda, la locomotora del crecimiento económico de cualquier país.

En otras palabras, la imposición de los países de Occidente de las sanciones dirigidas contra los sectores clave de la economía rusa agrava los problemas sistémicos de la economía nacional de ese país euroasiático, en particular su dependencia de la importación de productos de alta tecnología, falta de condiciones para la atracción de préstamos a precios razonables en el mercado doméstico y la dependencia de los ingresos del presupuesto estatal de los impuestos de las empresas exportadoras de los energéticos.

Para concluir, se puede afirmar que las sanciones introducidas por los países de Occidente contra Rusia han cambiado radicalmente las circunstancias del desarrollo económico de ese país. Rusia tiene que acostumbrarse a vivir en nuevas condiciones y movilizar todos sus recursos para sobreponerse a las limitaciones impuestas por los Estados Unidos y la Unión Europea. El éxito de Rusia va a depender no solamente de la eficiencia de la política económica y social encaminada a reanudar el crecimiento económico de ese país euroasiático, sino también de la puesta en marcha de las reformas estructurales e institucionales orientadas a la superación de la dependencia de Rusia de la producción y exportaciones de los hidrocarburos. Un papel importante podrían jugar el desarrollo de las relaciones económicas con los países que no han introducido sanciones contra Rusia, así como la búsqueda de fuentes de financiación alternativas.

\section{Bibliografía}

Afontsev, Serguey, "Vijod iz krizisa v usloviyaj sanktsiy: missiya nevypolnima?”, Voprosy ekonomiki, núm. 4, 2015.

Aganbeguián, Abel, "Vozrastayushiy korporativniy dolg pered inostrannymi investorami - "petliya na shee" nazionalnoy ekonomiki", Dengui $i$ kredit, núm. 3, 2013.

kogo rosta i dlia preodoleniya stagfliatsii, rezesii i stagfliatsii”, Dengui i kredit, núm. 2, 2015. 
Eder, Leontiy, "Nefteenergueticheskiy kompleks v ekonomike Rossii, en Mineralnye resursy Rossii”, Ekonomika i upravleniye, núm. 4, 2013.

Fondo Monetario Internacional, Perspectivas de la economía mundial, enero de 2015.

Fondo Monetario Internacional, World Economic Outlook (WEo), Uneven Growth: Short - and Long-Term Factors, abril de 2015.

Kazantsev, Serguey, "Antirossiyskiye sanktsii "vchera I segodniya”, EKO, núm. 3, 2015.

Kheyfets, Boris, Globalniy dolgovoy krizis i riski dolgovoy politiki Rossii, Moscú, 2012.

— , "Riski dolgovoy politiki Rossii na fone globalnogo dolgovogo krizisa", Voprosy ekonomiki, núm. 3, 2012.

Lijachov, Alexey, "Vneshniaya zadolzhennost i dolgovaya diplomatiya Rossii v perejodniy period", Vneshneekonomicheskiy bulleten, núm. 10, 2005.

Matovnikov, Mijail, "Problemy rossiyskogo vneshnego korporativnogo dolga namnogo slozhnee, chem rfzhtnsiya", Dengui i kredit, núm. 9, 2013.

Portanskiy, Alexey, Antirossiyskiye sanktsii - mery destructivnye I kontrproduktivnye, Dengui i kredit, núm. 10, 2014.

Semenov, Victor, "Vneshniaya zadolzhennost Rossii i latinoamerikanskiy opyt”, ME i MO, núm. 5, 1994.

Shabalin, Alexander, "Dinamika vneshnego golga bankov v sovremennoy Rossii”, Bankovskiye uslugui, núm. 2, 2014.

, "Dinamika gosudarstvennogo I korporativnogo dolga Rossii v usloviyaj ekonomicheskij sanktsiy", Vestnik instituta ekonomiki RAN, núm. 2, 2015.

_. "Gosudarstvenniy i korporativniy dolg Rossii v novyj usloviyaj", Bankovskoye delo, núm. 2, 2015.

Smitienko, Boris y Tatiana Sidorenko, "El endeudamiento externo de Rusia: situación actual y perspectivas”, Comercio Exterior, vol. 54, núm. 11, noviembre de 2004.

Tsvirko, Svetlana, "Problemy gosudarstvennogo I chastnogo dolga Rossii", Ekonomicheskoye vozrozhdeniye Rossii, núm. 1, 2014.

Uliukaev, Alexey y Mau Vladimir, "Ot ekonomucheskogo krizisa k ekonomicheskomu rostu, ili Kak ne dat krizisu prevratitsiya v stagnatsiyu”, Voprosy ekonomiki, núm. 4, 2015.

Vjozhdeniye Rossii v sotsialno-ekonomicheskiy krizis: tendentsii 2015 
goda i sravnitelny analiz. Informe analítico. Moscú, Centro analítico adjunto al Gobierno de Rusia, abril de 2015.

Vneshniy dolg Rossii i problemy ego uregulirovaniya, Moscú, 2002.

Zimenkov, Romuald, Rossiya: integratsiya v mirovuyu ekonomiku, Moscú, 2002. 